\title{
LICENÇA SOCIAL PARA OPERAR E IMPACTOS AMBIENTAIS: UMA REVISÃO DE LITERATURA
}

\author{
Cynthia Akemi Anno Franco \\ Mestranda em Ciências da Engenharia Ambiental \\ Universidade de São Paulo São Carlos - SP - Brasil \\ cy_akemi@hotmail.com \\ Carlos Danillo Cavalcante Sampaio \\ Mestrando em Engenharia Hidráulica e Saneamento \\ Universidade de São Paulo São Carlos - SP - Brasil \\ cdanillo@sc.usp.br \\ Maria Rita Raimundo e Almeida \\ Doutora em Ciências da Engenharia Ambiental \\ Universidade Federal de Itajubá Itajubá - MG - Brasil \\ maria.rita.ralmeida@gmail.com
}

\section{RESUMO}

Licença Social para Operar (LSO) é uma percepção da comunidade e sua aceitabilidade em relação a uma empresa e suas operações locais. Essa espécie de autorização informal fornecida pela sociedade à empresa tem se mostrado importante, uma vez que ambos saem ganhando: a população local, ao se sentir inserida na empresa e em tomadas decisões, e a empresa, em termos de confiança e aceitação para que esta inicie ou continue com suas atividades. A fim de contribuir para futuros trabalhos e discussões, foi realizada uma revisão bibliográfica sistemática com o objetivo de analisar como a literatura tem tratado o tema. A procura pelos trabalhos foi feita nas bases Scopus e Web of Science, sendo aplicados alguns critérios préestabelecidos para busca e triagem. Os resultados encontrados mostram que é um tema recente, com a maioria das publicações nos últimos 5 anos, sendo a metodologia de estudo de caso a mais utilizada e sua aplicação voltada, principalmente, para empreendimentos de mineração. A Austrália se destacou tanto como o país de origem das instituições de maior parte dos primeiros autores como dos estudos de caso trabalhados. A literatura retrata que a prática da LSO tem enfrentado desafios, como a distância entre teoria e prática, devido a contextos mutáveis, e o perigo de que a ferramenta seja usada de forma equivocada, não trazendo benefícios à comunidade. Assim, o tema LSO mostra-se emergente nas pesquisas científicas e significativo para os pesquisadores, sendo a revisão sistemática realizada relevante para pesquisas futuras.

Palavras-chave: Desenvolvimento sustentável. Licença social para operar. LSO. Responsabilidade social. Revisão sistemática.

\section{SOCIAL LICENSING TO OPERATE AND ENVIRONMENTAL IMPACTS: A LITERATURE REVIEW}

\begin{abstract}
Social License to Operate (SLO) is a perception of the community and its acceptability to a company and its local operations. This kind of informal authorization provided by the society to the company has proved to be important, since both win: the local population when feeling part of the company and in decision-making, and the company in terms of trust and acceptance to start or continue with its activities. In order to contribute to future works and discussions, a systematic bibliographical review was carried out with the aim of analyzing how the literature has dealt with the subject. The identification of the works was done in the Scopus and Web of Science bases, being applied some pre-established criteria for search and screening. The results found show that this is a recent theme, with the majority of publications in the last 5 years, being the case study methodology the most used and its application mainly focused on mining enterprises. Australia stood out as both the home country of the institutions of most of the first authors and of the case studies worked. The literature portrays that SLO practice has faced challenges, such as the distance between theory and practice due to changing contexts, and the danger that the tool may be misused, not bringing benefits to the community. Thus, the SLO theme is emerging in scientific research and is significant for researchers, being the systematic review performed relevant for future research.
\end{abstract}

Key words: SLO. Social License to Operate. Social responsibility. Systematic review. Sustainable development.

Data da submissão: $30 / 05 / 2019$

Data de aceite: $17 / 12 / 2019$ 


\section{INTRODUÇÃO}

O crescimento populacional e da ocupação do espaço geográfico aliados ao desenvolvimento e ao avanço dos meios de transporte, comunicação e serviços, a necessidade de mão de obra qualificada e a possibilidade de contratação de profissionais acabam criando um cenário em que empresas e comunidades estão cada vez mais próximas, sem que, contudo, fiquem claras quais as consequências que a instalação de uma indústria pode causar localmente. Nesse contexto, o conceito de Licença Social para Operar (LSO) se apresenta, então, para buscar um ideal de empreendimentos mais participativos, criando uma relação de proximidade com os stakeholders e, principalmente, com a comunidade afetada, contribuindo para a minimização de conflitos socioambientais e para a sustentabilidade das relações entre os grupos envolvidos.

Pode-se entender a Licença Social para Operar como uma abordagem conceitual que uma organização aplica no envolvimento com as comunidades e partes interessadas, auxiliando na identificação de ações proativas que as empresas podem tomar para aumentar a probabilidade de que elas irão desfrutar do apoio das comunidades onde trabalham (Jijelava \& Vanclay, 2014).

A LSO propõe uma visão sistêmica, integrando os desafios sociais aos já habituais recursos tecnológicos, de produção e desafios de gerenciamento (Santiago \& Demajorovic, 2016) e está diretamente ligada à forma como as empresas definem e compreendem o desenvolvimento sustentável (Bice, 2014). Assim, essa espécie de autorização informal fornecida pela sociedade às empresas tem se mostrado importante, uma vez que ambos saem ganhando: as partes interessadas e a população afetada ao se sentirem relevantes para a tomada de decisões, e a empresa em termos de segurança e aceitação para que esta inicie ou continue com suas atividades.

Para que um empreendimento obtenha a LSO, é preciso basicamente que o projeto em questão tenha assegurado sua legitimidade jurídica, social e econômica (Vanclay, 2017). Com o intuito de embasar as discussões acerca do tema, as pesquisas sobre LSO têm apresentado orientações sobre como estabelecer uma boa comunicação com as partes envolvidas em todas as etapas da implementação de um projeto, bem como sobre a resolução de conflitos (Prno, 2013). Deste modo, a licença social é algo que tem chamado a atenção de empresas que atuam em setores com grande impacto socioambiental e tem sido uma narrativa bem estabelecida no mundo corporativo, mas sua aceitação tem sido particularmente extensa no setor de mineração (Curran, 2017). Para as empresas mineradoras, o conceito de LSO está baseado na ideia de que estas não precisam apenas das autorizações do governo, mas também de uma "permissão social" para conduzir seus negócios (Ranängen \& Lindman, 2018).

No Brasil, a LSO vem sendo incorporada pela retórica de institutos, fundações e empresas, com um conjunto de práticas a ela associadas. Observa-se o crescente número de empresas mineradoras que a associam a suas construções discursivas relativas às políticas e aos programas sociais ou de relacionamento comunitário, isto é, ao universo vocabular mais conhecido por "responsabilidade social", "investimento social privado" e "sustentabilidade". De forma conexa, ela também tem sido abraçada por instituições que servem de apoio à idealização de ações sociais das empresas (Gaviria, 2015).

Embora a questão da LSO esteja se tornando cada vez mais proeminente em debates que tratam do papel do controle social sobre empresas de alto nível social e impacto ambiental, casos como o rompimento da barragem da Samarco reforçam a necessidade de melhor entendimento de como essa abordagem pode ser aplicada efetivamente em contextos de vulnerabilidade: no referido caso, a LSO pode ter melhor servido aos interesses da empresa do que aos da comunidade, pois seus aspectos socioambientais e programas compensatórios enfraqueceram a capacidade crítica dos grupos locais e contribuíram para a política de demissão em vez de promover um processo de legitimação (Demajorovic, Lopes, \& Santiago, 2019). Logo, são necessários estudos que abordem e avaliem a prática da LSO e proponham melhorias.

Revista de Gestão Social e Ambiental - RGSA, São Paulo, v. 13, n. 3, p. 60-78, set./dez. 2019. 
Neste sentido, e visto que a LSO é um tema relativamente recente, tem-se como objetivo neste artigo a apresentação de uma revisão sistemática sobre ela, a fim de analisar como a literatura tem tratado o tema e de contribuir para futuros trabalhos e discussões, além de contribuir para a utilização prática do instrumento. Assim, a pergunta que norteou a pesquisa foi como a LSO vem sendo tratada pela literatura no contexto socioambiental.

Optou-se por usar a revisão sistemática (RS), uma vez que ela é a metodologia de síntese de evidências que são agora amplamente utilizadas em setores da sociedade onde a ciência pode informar a tomada de decisões e se tornou um padrão reconhecido para acessar, avaliar e sintetizar informações científicas; a necessidade de rigor, objetividade e transparência na obtenção de conclusões a partir de um corpo de informações científicas é evidente em muitas áreas da política e da prática, da medicina clínica à justiça social. $\mathrm{O}$ ambiente e a forma como eles são administrados não são exceção e há muitos problemas urgentes para os quais precisamos de uma fonte confiável de evidências para fundamentar ações (CEE, 2013).

O trabalho está organizado em tópicos que buscam apresentar a fundamentação teórica da LSO, a descrição da metodologia e dos procedimentos empregados na pesquisa, os resultados encontrados, bem como a sua análise e discussão, culminando com a apresentação das considerações finais que visam destacar os principais achados.

\section{FUNDAMENTAÇÃO TEÓRICA}

O conceito da Licença Social para Operar (LSO) teve origem na indústria mineradora no final da década de 1990, quando as empresas passaram a entender melhor seus desafios na gestão dos riscos políticos e sociais em torno de seus projetos (Cooney, 2017) juntamente com a aproximação das comunidades afetadas por empreendimentos com os meios de comunicação emergentes, que passaram a expressar suas preocupações fazendo uso de novas tecnologias (Bice \& Moffat, 2014). O uso contemporâneo do termo Licença Social para Operar (LSO) pretende sugerir que as comunidades têm tanta autoridade quanto os governos na concessão de permissões ou "licenças". O termo foi utilizado, neste contexto, pela primeira vez em 1997, por um executivo de mineração chamado James Cooney. Ele havia notado que muitas empresas de mineração estavam perdendo dinheiro por causa da resistência da comunidade que encontraram quando tentaram iniciar novos projetos ou expandir projetos existentes (Boutilier, 2014). No entanto, o uso da LSO já extrapolou o setor de exploração mineral, sendo debatido em outros setores, tais como infraestrutura, energia e turismo (Koivurova et al., 2015).

A LSO é uma percepção da comunidade sobre a aceitabilidade de uma empresa e suas operações locais (Boutilier \& Thomson, 2011) e sua proposta baseia-se na ideia de que a sociedade pode dar ou recusar o apoio à uma empresa e suas operações (Prno, 2013; Moffat \& Zhang, 2014). Ela emerge como um elemento complementar aos mecanismos formais de controle das empresas, como, por exemplo, a legislação ambiental, de forma a assegurar a legitimidade das organizações (Santiago et al., 2018). Assim, é independente das licenças ambientais reguladas pelos governos, sendo informalmente garantida pela sociedade (Cruz et al., 2019).

Deve-se pensar a LSO como instrumento político que relaciona o governo, a comunidade, os profissionais e os proponentes. Dessa forma, não é uma licença simples e sim múltipla, pois uma vez que há aceitação entre os grupos envolvidos, não será apenas matéria de confiança, mas sim de intervenções práticas e efetivas que buscarão atenuar e solucionar os impactos negativos gerados pelo projeto (Wedin et al., 2013).

O conceito de comunidade pode ser entendido como os stakeholders que compartilham interesses comuns com relação a um projeto, sejam eles afetados diretamente pela implantação de um determinado empreendimento ou não. Atualmente, essas partes interessadas exigem que as empresas se alinhem mais estreitamente com os princípios do desenvolvimento sustentável, dos quais o aumento da participação da comunidade na tomada de decisões é um objetivo central (Prno \& Slocombe, 2012). Ainda, a teoria das partes interessadas postula que as empresas são 
responsáveis por oferecer benefícios a todos os stakeholders, e não apenas aos acionistas e clientes (Jones, Felps, \& Bigley, 2007).

Conflitos entre empresas e comunidades locais representam riscos para o negócio e decorrem da percepção, cada vez maior por parte das empresas, dos custos associados aos conflitos (Franks et al., 2014). Do ponto de vista da empresa, a LSO contribui para minimizar riscos aos negócios e garantir sua reputação (Owen \& Kemp, 2013). Neste contexto, a LSO traz para a pauta das engenharias que atuam na área de gestão de risco, a necessidade de também considerarem o viés social do risco (Santiago et al., 2018).

Os conceitos "reputação" e "licença social" estão intimamente relacionados, na medida em que desfrutar de uma boa reputação corporativa diante das comunidades locais ajuda a fortalecer as condições da licença social, diminuindo, por conseguinte, o risco de conflitos e oposições locais (Gunningham, Kagan, \& Thornton, 2004).

O nível de aceitação das partes interessadas pode variar e Boutilier \& Thomnson (2011) identificaram quatro níveis da LSO representados pela Figura 1. Eles alegam que o nível de SLO concedido a uma empresa está inversamente relacionado ao nível de risco sociopolítico que uma empresa enfrenta. Uma LSO baixa aponta um risco maior, o qual implicaria na perda da mesma, indicando que o projeto está em perigo de acesso a recursos essenciais (financiamento, licenças legais, matéria-prima, mão-de-obra, mercados, infraestrutura pública). Um nível maior de LSO é a aceitação do projeto, onde essa camada cobre a maior área para indicar que é o nível comum de licença social concedido. Se a empresa estabelece sua credibilidade, a licença social sobe para o nível de aprovação. Com o tempo, se a confiança é estabelecida, a licença social pode chegar ao nível de identificação psicológica, onde o nível de risco sociopolítico é muito baixo (Boutilier \& Thomnson, 2011).

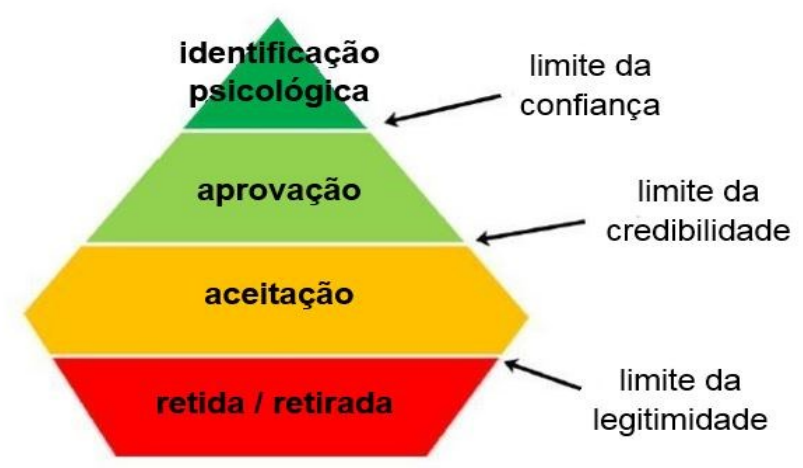

Figura 1. Níveis de Licença Social para Operar

Fonte: Thomnson \& Boutilier, (2011)

Estudiosos da LSO propõem estratégias para obtê-la e mantê-la, incluindo a necessidade de comunicação antes e depois da implementação do projeto, a transparência na disseminação da informação e o desenvolvimento de mecanismos para resolução de conflitos e para processos de tomada de decisão culturalmente adequados (Prno, 2013). Exalta-se, ainda, que a multidimensionalidade das relações para obtenção da licença depende da qualidade das relações estabelecidas, de forma a deixar que se observe melhor as relações e os interesses e como eles se desenvolvem ao longo do tempo, pois a sua mudança pode comprometer o processo (Parsons \& Moffat, 2014).

As formas pelas quais as empresas acreditam que podem obter e manter sua licença social para operar estão consistentemente ligadas às suas definições e conceituações do desenvolvimento sustentável (Bice, 2014). Se estes forem deficientes, as empresas podem empregar técnicas de neutralização de discursos opositores no seu processo de construção da LSO ampliando a confiança 
local em suas atividades ao mesmo tempo em que situações de risco ou mesmos impactos negativos de suas ações são encobertas (Meesters \& Behagel, 2017).

\section{MÉTODO DE PESQUISA}

A metodologia usada consiste de uma Revisão Sistemática. Ela começa com uma pergunta, seguindo para a coleta e sintetização dos dados existentes para tentar responder a esta pergunta e, de acordo com a CEE (2013), consiste em sete etapas básicas apresentadas na Figura 2. A metodologia escolhida teve como propósito responder a seguinte questão de pesquisa: Como a LSO vem sendo tratada pela literatura no contexto socioambiental?

O protocolo e a busca de trabalhos iniciaram-se com a seleção das bases científicas de dados, sendo escolhidas a Scopus e Web of Science. A busca por trabalhos foi realizada utilizando as palavras-chave em inglês: "social license to operate", "social license", "social licence to operate", "social licence". A variação gramatical das palavras se dá por conta do emprego do termo nos Estados Unidos ser "license", tanto para o substantivo quanto para o verbo; já nos demais países de língua inglesa, geralmente, é utilizada a palavra "license" para verbo e "licence" para o substantivo. Ainda, optou-se por buscar os termos entre aspas de modo que não fossem retornados trabalhos que não tivessem como foco a LSO. A busca foi realizada em novembro de 2018.

A triagem dos artigos encontrados nas bases de dados foi realizada com base nos critérios descritos a seguir:

a. Tipos de publicações: Artigos científicos indexados e revisões que são as formas de publicação mais relevantes. Foram eliminadas publicações referentes a capítulos de livros, publicações com erro e indisponibilidade do arquivo.

b. Idioma: Foram considerados apenas artigos e revisões publicadas na língua inglesa, por ser o principal idioma de divulgação científica.

c. Área de pesquisa: Foram considerados apenas artigos publicados na área 'Environmental Science', a fim de focar a seleção em trabalhos que pudessem dar o contexto socioambiental, estando alinhado com a questão a ser respondida pela pesquisa.

d. Título: Os artigos restantes foram analisados verificando se as palavras-chave estavam presentes no título e, se pelo título, o trabalho era de interesse para responder à questão de pesquisa.

e. Resumo: Após serem filtrados pelo critério do título, foram verificados nos resumos dos artigos se a licença social era um dos principais temas discutidos e se este tinha informação para responder à questão de pesquisa.

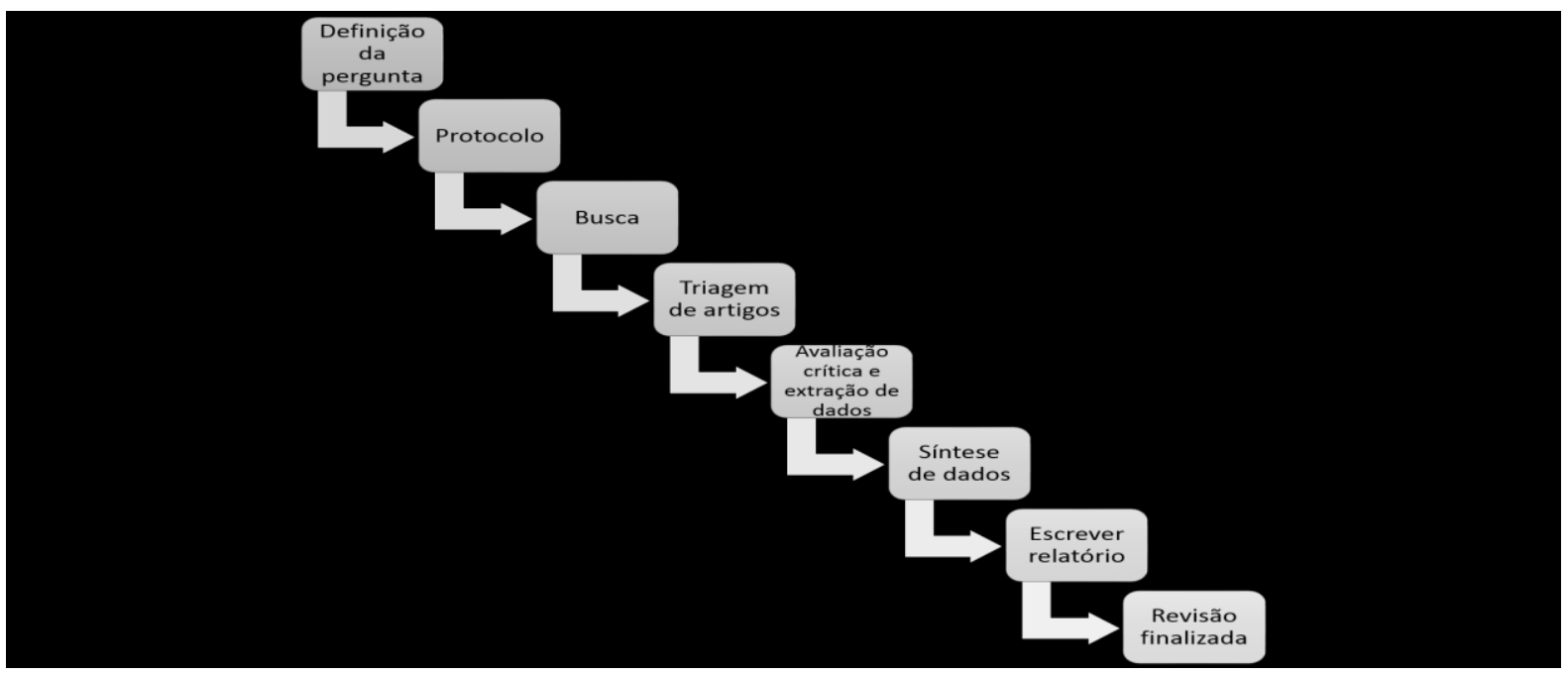

Figura 2. Etapas básicas na condução de uma revisão sistemática.

Fonte: Adaptado de CEE, (2013) 
Ao verificar o resumo dos artigos selecionados, foram identificados seis trabalhos que se repetiam nas duas bases de dados. Estes foram considerados apenas uma vez na plataforma Scopus, sendo eliminados da plataforma Web of Science. Os artigos selecionados seguiram para a etapa posterior de avaliação e extração de dados. O processo de triagem dos artigos é representado na Tabela 1.

Tabela 1. Síntese da etapa de triagem da revisão sistemática

\begin{tabular}{|c|c|c|c|}
\hline \multirow{2}{*}{ Etapa } & \multirow{2}{*}{ Filtro } & \multicolumn{2}{|c|}{$N^{0}$ de artigos } \\
\hline & & Web of Science & Scopus \\
\hline 1 & Busca por palavras-chave & 13 & 388 \\
\hline 2 & Tipo de publicação & 13 & 245 \\
\hline 3 & Idioma & 13 & 242 \\
\hline 4 & Área de pesquisa & 12 & 133 \\
\hline 5 & Título & 8 & 55 \\
\hline 6 & Resumo & 7 & 54 \\
\hline 7 & $\begin{array}{l}\text { Extração de dados e análise da } \\
\text { conclusão }\end{array}$ & 7 & 54 \\
\hline \multicolumn{2}{|c|}{ Artigos repetidos nas duas bases } & \multicolumn{2}{|c|}{6} \\
\hline \multicolumn{2}{|c|}{ Total analisado } & \multicolumn{2}{|c|}{55} \\
\hline
\end{tabular}

Fonte: Os autores

A partir desta etapa, foi iniciada a análise crítica e extração de dados dos artigos com base em uma lista de aspectos a serem avaliados: Título, palavras-chave, ano de publicação, periódico publicado, autores, país de origem da instituição dos autores e países onde foram realizados estudos de caso. Após o levantamento dessas informações, foi verificado o tipo de metodologia utilizada (estudo de caso, revisão bibliográfica, discussão, proposição de modelos, entre outros) e a conclusão do artigo, que foi analisada com o objetivo de responder a seguinte pergunta: $\mathrm{O}$ que o autor concluiu sobre a LSO?

A avaliação crítica e extração de dados dos artigos foram realizadas pelos autores em paralelo, ambos os resultados foram discutidos para estabelecer um consenso entre os pares. Posteriormente, os resultados finais foram tabulados e os artigos organizados em grupos divididos por tipo de metodologia utilizada (estudo de caso ou revisão bibliográfica sobre o tema). A partir da divisão por grupos, foi iniciada a interpretação com relação às respostas das perguntas realizadas na lista de verificação dos artigos. Assim, foram cumpridas as três últimas etapas da condução da RS: síntese dos dados, elaboração de relatório e revisão finalizada.

\section{RESULTADOS DA PESQUISA}

A revisão dos artigos científicos sobre a Licença Social para Operar resultou, inicialmente, no levantamento de 13 publicações disponíveis na base de dados Web of Science, e 388 publicações no Scopus, na etapa 1. Após a última etapa de filtragem, obteve-se um total de sete artigos da base Web of Science e 54 artigos da base Scopus. Destes artigos, seis apareceram repetidamente nas duas bases de dados, resultando então 55 artigos diferentes ao final de todas as etapas. 
Os trabalhos foram publicados no intervalo de tempo de 2011 a 2018 , no entanto, o maior número de publicações se concentra no período de 2014-2017, com o pico no ano de 2017, responsável por 18 das publicações analisadas, como mostra a Figura 3.

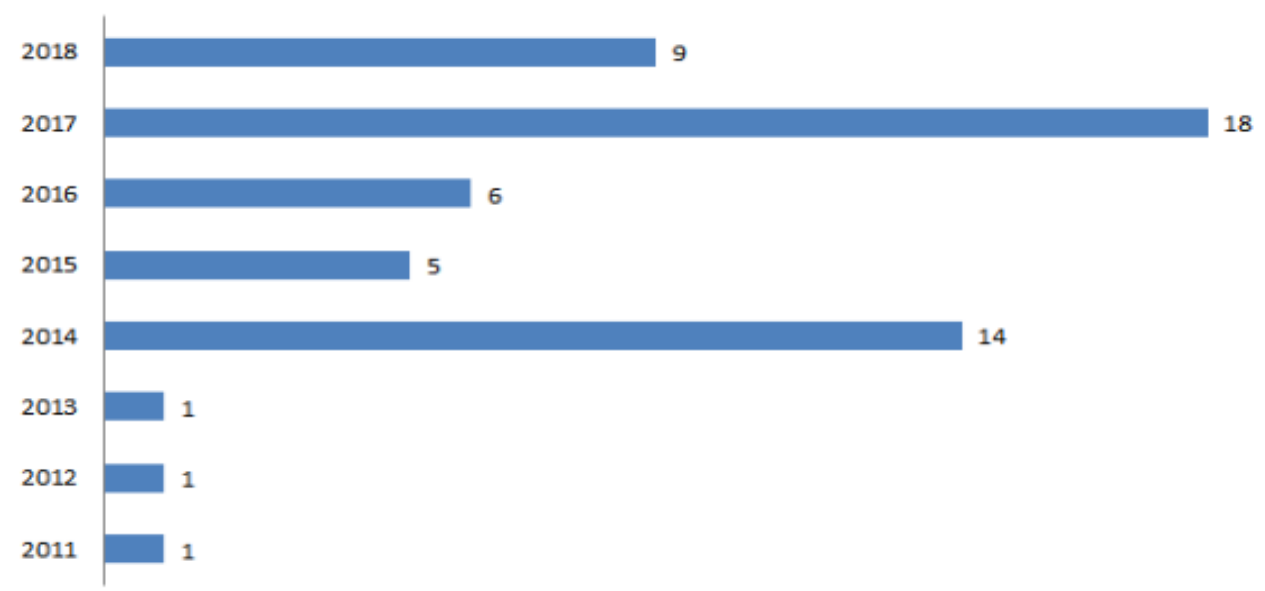

Figura 3. Número de artigos selecionados por ano de publicação.

Fonte: Os autores

Os periódicos de maior publicação foram Impact Assessmentand Project Appraisal, Journal of Cleaner Production e Resources Policy, com sete, oito e 14 publicações respectivamente, como pode ser observado na Figura 4.

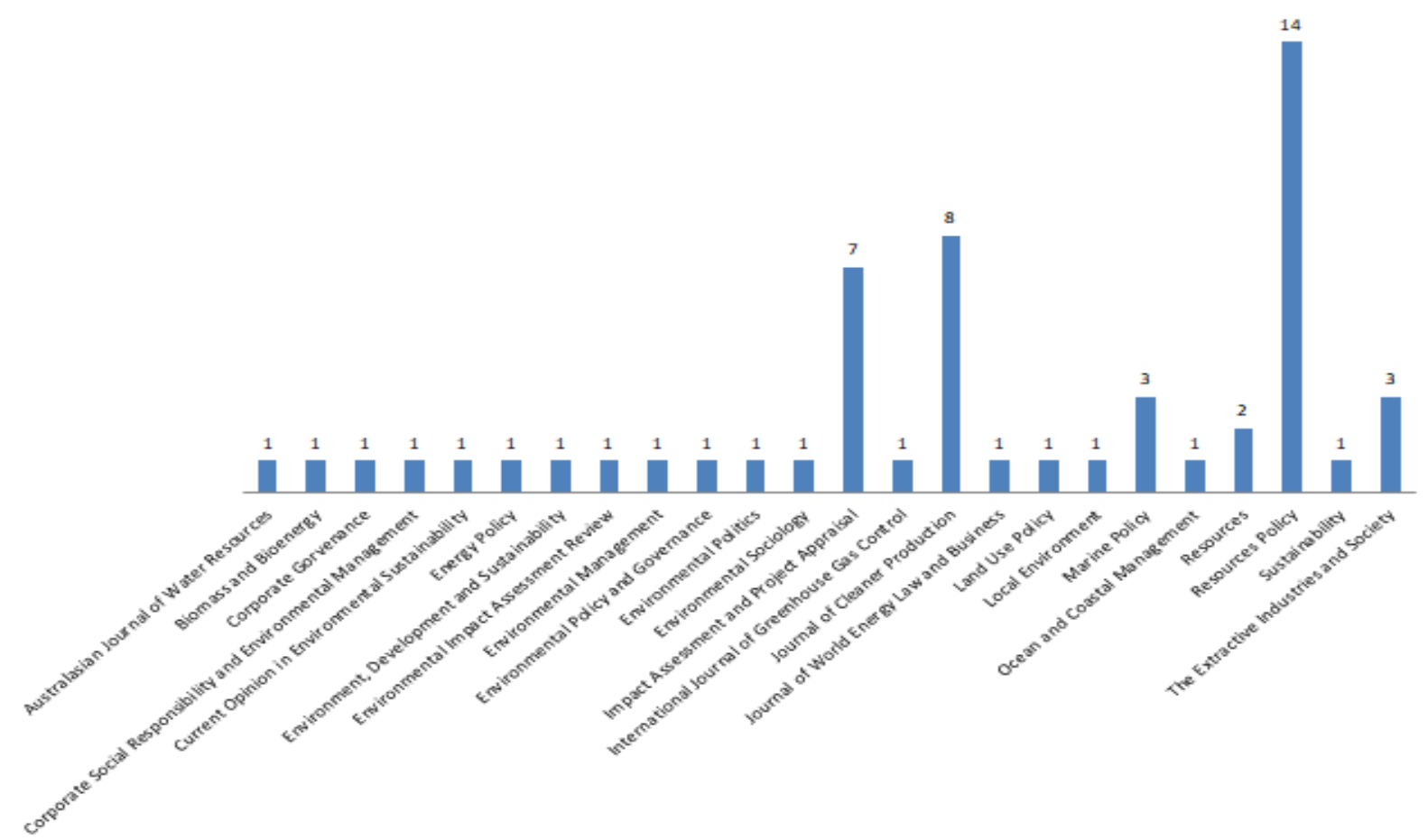

Figura 4. Número de artigos selecionados por periódico

Fonte: Os autores

Dentre os artigos revisados, foi possível observar que os autores que mais publicaram, como primeiro ou coautor sobre o tema dentre os artigos selecionados para análise desta revisão, foram: Moffat, K. (seis artigos), Vanclay, F. (cinco artigos) e Bice, S. (três artigos) (Figura 5). 


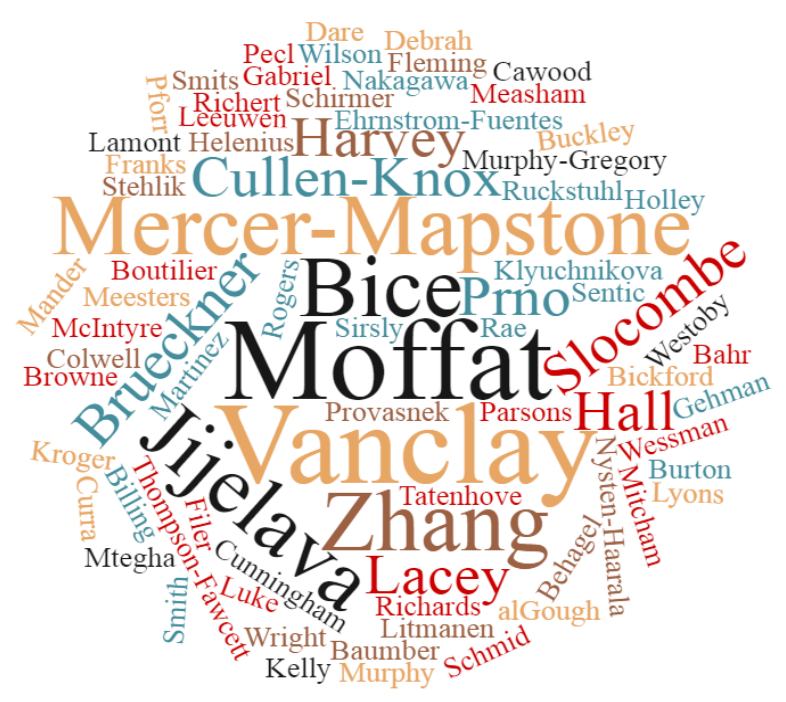

Figura 5. Nuvem dos autores encontradas nos artigos analisados Fonte: Os autores

O levantamento sobre os países nos quais estão localizadas as instituições onde as pesquisas sobre o tema da Licença Social estão sendo realizadas levou em consideração apenas a origem do primeiro autor dos artigos analisados. Os autores que publicaram mais de um artigo na primeira posição do ordenamento foram considerados apenas uma vez. Como demonstrado na Figura 6, a Austrália se posiciona em contraste com os outros países, liderando o ranking de autores que publicaram sobre o tema.

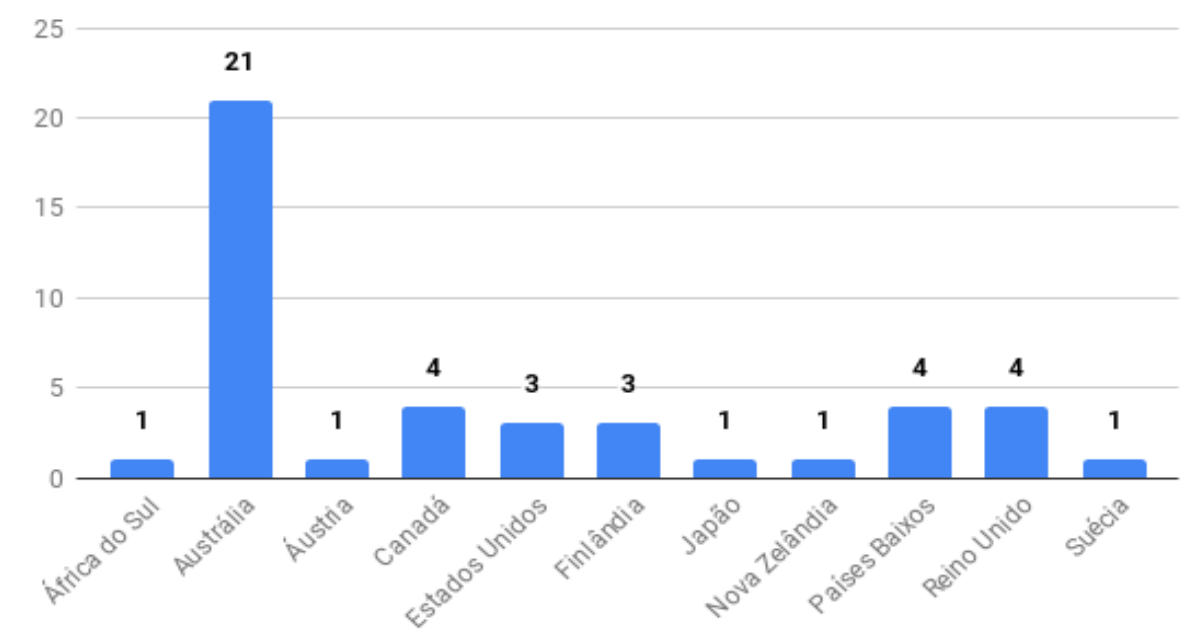

Figura 6. Relação dos países de origem das instituições dos primeiros autores

Fonte: Os autores

O alto número de instituições australianas, pesquisando sobre o tema da Licença Social para Operar, pode se justificar por conta de a indústria de mineração australiana servir como um excelente ponto de partida para entender como as corporações contemporâneas definem sua Licença Social para Operar (Bice, 2014). A comunidade australiana e outras partes interessadas estão se tornando cada vez mais conscientes de sua influência nas operações, e as responsabilidades da corporação em proteger o meio ambiente local, a economia e a comunidade aumentaram reflexo disso (Hall, 2015).

As palavras-chave que mais foram utilizadas pelos autores analisados estão representadas pela nuvem da Figura 7. As que obtiveram maior destaque foram a palavra "social", que apareceu 
65 vezes; seguida da palavra "operate", que apareceu 30 vezes. As variações gramaticais da palavra "licence" foram utilizadas por 22 autores, enquanto a "license" foi utilizada por 19 autores. Algumas outras palavras-chave de destaque utilizadas foram "responsibility" (12 vezes), e a palavra "mining" que também aparece 12 vezes, indicando que boa parte dos artigos vinculou o tema da LSO com a tipologia do empreendimento de mineração, conforme já havia sido apontado por Curran (2017), que disse que a LSO era mais comum para esta tipologia. A palavra "corporate" foi citada 10 vezes e outras palavras como "stakeholder", "development", "engagement" e "community" apareceram oito vezes nos artigos analisados.

Quanto à metodologia, foi possível perceber que a maior parte dos autores (30) utilizou em seus trabalhos o estudo de caso; outros 11 optaram pelo método de revisão da literatura; e 14 tiveram como abordagem metodológica a discussão sobre o tema da LSO, a concepção e aplicabilidade de modelos, levantamento de informações por meio de questionários ou análise de documentos e relatórios.

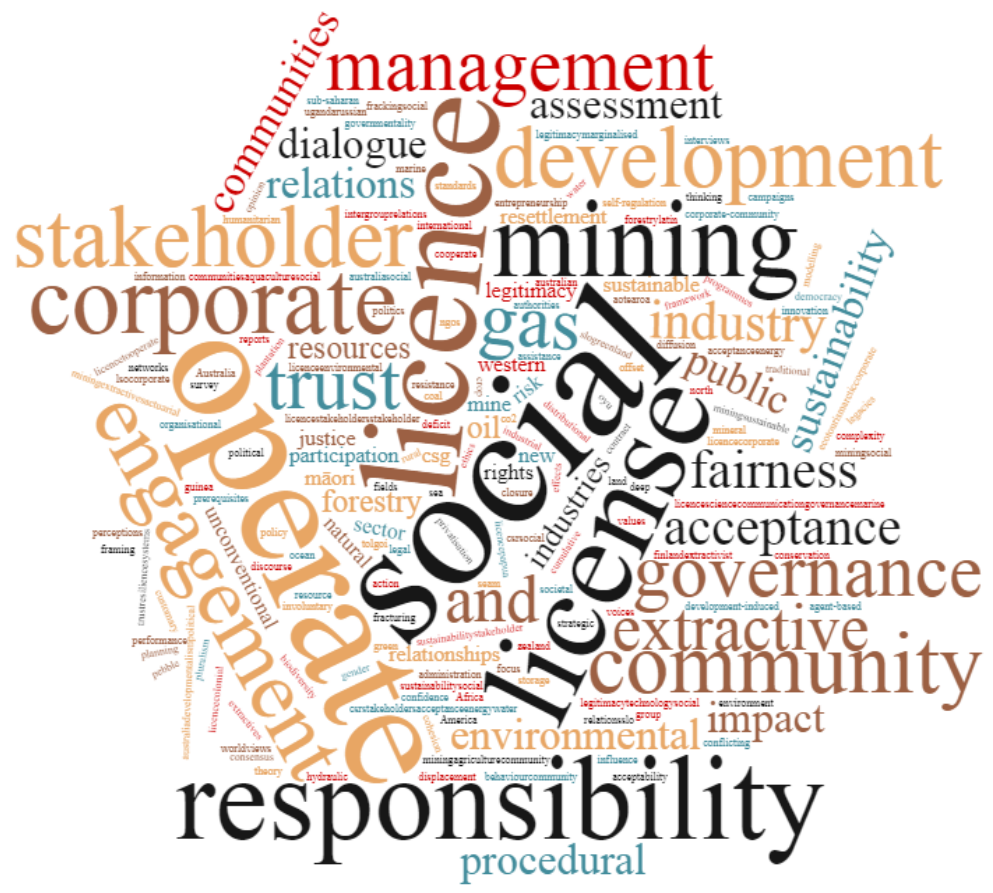

Figura 7. Nuvem de palavras-chave encontradas nos artigos analisados Fonte: Os autores

Os países onde os estudos de caso foram realizados pelos autores que utilizaram esta estratégia em seus artigos estão representados na Figura 8. Dos artigos que aplicaram estudos de caso em mais de um país, cada um deles foi contabilizado separadamente.

É possível perceber que o país australiano se destaca como cenário para realização de pesquisas sobre a Licença Social. Os artigos revisados que fizeram uso do estudo de caso na Austrália buscaram analisar a problemática das licenças sociais de uma atividade mineradora (Browne, Stehlik, \& Buckley, 2011); examinar a LSO da indústria de mineração da Austrália Ocidental no contexto da agenda "desenvolvimentista" do estado (Brueckner, Durey, Pforr, \& Mayes, 2014); descrever como a LSO se manifestou na governança marinha australiana (CullenKnox, Haward, Jabour, Ogier, \& Trace, 2017); explorar a dinâmica da oposição da comunidade a projetos de mineração de carvão (Curran, 2017); compreender como o envolvimento da comunidade desempenha um papel na obtenção da licença social (Dare, Schirmer, \& Vanclay, 2014); examinar a LSO comparando o uso desse conceito em quatro contextos da indústria de energia australiana: mineração, eólica, captura e armazenamento de dióxido de carbono e 
geotérmica (Hall, Lacey, Carr-Cornish, \& Dowd, 2015); explorar como as formas de contrato social baseadas no consentimento e na justiça fornecem uma estrutura ética para o modo como as indústrias de gás de carvão e as comunidades interagem (Lacey \& Lamont, 2014); unir dados empíricos de uma pesquisa eleitoral com a dinâmica da resistência social que leva a retirada da LSO, para entender como duas comunidades reagem ao desenvolvimento da indústria de gás de carvão (Luke, 2017); desenvolver e testar um modelo explorando correlações entre um mecanismo de engajamento, diálogo e relações empresa-comunidade considerando elementos da LSO em comunidades próximas a atividades de mineração (Mercer-Mapstone, Rifkin, Louis, \& Moffat, 2018); medir e modelar elementos críticos a LSO em uma região de mineração (Moffat \& Zhang, 2014); avaliar a estratégia da LSO no contexto da literatura de governança (Murphy-Gregory, 2018); e avaliar a LSO concedida pela população da Austrália Ocidental ao setor de petróleo e gás (Richert, Rogers, \& Burton, 2015). Dentre os 12 artigos que desenvolveram estudos de caso na Austrália, 11 deles apresentam como instituições de origem do primeiro autor universidades australianas.

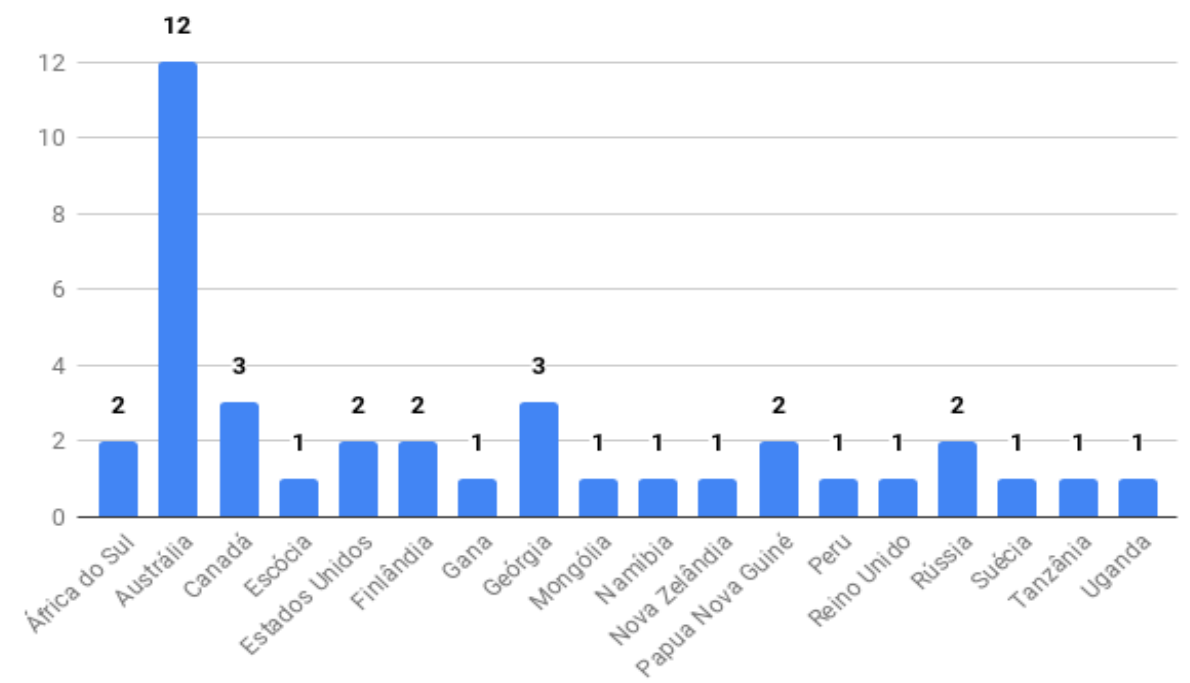

Figura 8. Países onde foram realizados os estudos de caso Fonte: Os autores

Nos trabalhos analisados, é possível perceber que os empreendimentos de mineração são frequentemente citados pelos autores, por conta dos impactos causados por esta atividade no meio social e ambiental e também pela tipologia estar diretamente relacionada com a origem da prática da Licença Social para Operar. Além da mineração, a obtenção da LSO por outras tipologias de empreendimento e atividades também vêm sendo retratadas pela literatura, como nos estudos sobre o contexto social da captura e armazenamento de carbono (Gough, Cunningham, \& Mander, 2018), na gestão da água em larga escala (Hall, 2015), para grandes projetos hidrelétricos (Jijelava \& Vanclay, 2018), estudos sobre o cultivo de energia celulósica, os quais apresentam sua expansão dependente da aceitação de comunidades locais (Baumber, 2018). O ecoturismo também foi apontado como uma vertente que necessita da obtenção da LSO, e que deve aprender com as grandes indústrias extrativistas onde deve obter a aprovação da comunidade como parte de um processo de avaliação de impacto ambiental (Bickford, Smith, Bickford, Bice, \& Ranglack, 2017).

Na prática, a LSO se oferece para complementar a teoria dos stakeholders e a literatura e prática da Responsabilidade Social Corporativa (RSC), fornecendo uma meta compartilhada para as partes interessadas da indústria e da comunidade na negociação de propostas de desenvolvimento (Hall et al., 2015). O mais apropriado é que as empresas, especialmente as extrativistas, atuem de forma transparente, à medida que evitem os programas de desenvolvimento social que objetivam a caridade e os subsídios desnecessários ou indesejados pelas comunidades (Harvey \& Bice, 2014). 


\section{ANÁLISE E DISCUSSÃO DOS RESULTADOS}

Para remontar às conclusões e ao que foi discutido pelos artigos analisados, as informações foram agrupadas em tópicos. Este agrupamento surgiu a partir do que os artigos relatavam, também estava alinhado à pergunta de pesquisa de como a LSO vem sendo tratada pela literatura no contexto socioambiental e visava trazer orientações para estudos e prática desse tipo de licença. Assim, optou-se por abordar três questões: LSO e o contexto socioambiental, desafios da LSO e proposição de orientações para a LSO, conforme descrito a seguir.

\subsection{LSO e o contexto socioambiental}

Com relação ao contexto socioambiental, alguns autores afirmam que a preocupação com a proteção ambiental influencia na concessão da LSO por parte da comunidade, sendo necessário à companhia ou empresa manter um diálogo claro sobre as medidas mitigadoras e de compensação dos impactos (Billing, 2018; Brueckner et al., 2014; Litmanen, Jartti, \& Rantala, 2016; Martinez \& Franks, 2014; Meesters \& Behagel, 2017; Vanclay, 2017; Wessman, Kohl, Kinnunen, Saarivuori, \& Mroueh, 2014).

Na prática australiana de articulação da LSO por mineradoras, as questões sociais tendem a não receber tanta atenção na arena do desenvolvimento sustentável quanto às questões ambientais e de emprego (Bice, 2014); no entanto, para uma transformação ser bem-sucedida levando em conta a eco inovação, é essencial a inclusão dos fatores sociais (Provasnek, Sentic, \& Schmid, 2017).

Alguns estudos evidenciam as relações da LSO com a realidade de grupos específicos que podem ser mais sensíveis à instalação e operação de um determinado empreendimento. Comunidades em condições de pobreza extrema esperam que as empresas coloquem em prática ações que visem à criação de empregos e melhoria da infraestrutura de transporte local com o objetivo maior de fornecer as ferramentas necessárias para se desenvolverem, afastando a visão de que os mais pobres esperam apenas por caridade e assistencialismo (McIntyre, Murphy, \& Sirsly, 2015). Por uma perspectiva de gênero, há desafios na obtenção de uma LSO de mulheres, e mesmo os projetos bem-intencionados, destinados a levar o desenvolvimento a uma comunidade local, podem representar um risco significativo de prejudicar ainda mais aqueles que já estão em desvantagem (Jijelava \&Vanclay, 2014). Já as comunidades indígenas representam grupos não convencionais na articulação da LSO, pois têm direitos históricos de governança e direitos constitucionais distintos. Os impactos dos projetos extrativistas, em razão de sua escala e longo prazo, têm o potencial de afetar seriamente a "integridade cultural das comunidades indígenas" e para um processo de LSO tangível é preciso realizar uma parceria duradoura no que diz respeito à tomada de decisão sobre o uso de recursos (Ruckstuhl, Thompson-Fawcett, \& Rae, 2014). Para as comunidades tradicionais de reservas florestais, a implantação e a operação de empreendimentos podem gerar conflitos locais sobre o uso e ocupação das terras, levando a um inevitável fracasso na obtenção da LSO (Westoby \& Lyons, 2016).

Outro problema que afeta principalmente grupos de risco ocorre quando um empreendimento encerra suas atividades subitamente após conquistar uma LSO da comunidade afetada, de modo a gerar impactos e conflitos; os sacrifícios e investimentos não contratuais (sociais, psicológicos, econômicos e ambientais) representam um custo não contabilizado do fracasso e é preocupante que, numa sociedade cada vez mais definida pela incerteza e pelos riscos (ambientais, sociais, políticos, econômicos), essas questões não sejam levadas em conta no planejamento de projetos e que não seja fornecido seguro adequado para comunidades envolvidas em tais licenças sociais (Browne et al., 2011).

Os processos que envolvem gerenciamento de recursos ambientais necessitam de clareza e transparência, algo difícil de obter a partir de um conceito de LSO ainda em construção e sujeito a diversas interpretações. Uma metodologia mais formal para alcançar elementos-chave da LSO,

Revista de Gestão Social e Ambiental - RGSA, São Paulo, v. 13, n. 3, p. 60-78, set./dez. 2019. 
como confiança e legitimidade, pode assegurar que o caminho para se estabelecer uma LSO não precise ser remodelado a cada desenvolvimento aplicado (Van Putten et al., 2018).

Assim, no contexto socioambiental, a função da LSO é trazer enfoque na resolução dos conflitos sociais trazidos pelo empreendimento e na preocupação e no atendimento às minorias socialmente mais vulneráveis, tais como pobres, mulheres, indígenas, entre tantos outros. Isso é importante, pois, muitas vezes, atualmente despende-se mais atenção ao ambiental que ao social.

\subsection{Desafios da LSO}

A preservação do ambiente é importante na manutenção do estilo de vida de comunidades locais, sobretudo daquelas que dependem de forma mais direta dos recursos naturais locais. Neste sentido, um dos grandes desafios para as organizações de desenvolvimento é garantir que os interesses de todos os grupos vulneráveis não sejam negligenciados. Quando uma organização começa a trabalhar em uma comunidade, é relativamente fácil se conectar com pessoas ativas em posições dominantes e com grupos comunitários organizados, mas é difícil alcançar aqueles que são silenciosos ou incapazes de defender seus interesses (Jijelava \&Vanclay, 2014).

Entender que as empresas têm responsabilidade e desempenham um papel na sociedade, no meio ambiente e na vida dos locais é muito importante (Bickford et al., 2017). Ganhar aceitação social é especialmente relevante para as companhias que trabalham em setores onde o risco de reputação é alto, como no setor extrativista, e não ter uma LSO pode ter consequências significativas para os projetos (Jijelava \& Vanclay, 2017). No entanto, ainda existem lacunas entre os ideais teóricos da licença social e as formas utilizadas para obtenção da mesma (Bice, 2014).

É necessário ter cautela antes de afirmar que uma empresa, investimento ou indústria alcançou uma LSO abrangente em nível local (Ehrnstrom-Fuentes \& Kroger, 2017). O uso do termo LSO está se espalhando para diferentes indústrias, profissões e setores sociopolíticos, mas nem sempre com o mesmo entendimento de suas conotações e implicações. O perigo é que o significado possa se tornar tão obscuro que seu valor como ferramenta para promover a colaboração se torna obscurecido ou perdido (Boutilier, 2014).

Uma parte dos estudos analisados busca respostas para os conflitos que permeiam a LSO, por meio da observação das interações entre os interessados com a licença, e a prática que envolve esse processo. A legitimidade do conhecimento e da informação subjacentes a uma LSO e os resultados de políticas que estão sendo retidas ou concedidas estão começando a ser questionados pelos principais interessados (Cullen-Knox et al., 2017). A maneira como o conceito de LSO é entendido e passado da empresa para a comunidade pode abrir espaço para conflitos e decadência da reputação construída pela empresa (Curran, 2017; Filer \& Gabriel, 2018; Holley \& Mitcham, 2016; Kelly, Pecl, \& Fleming, 2017; Jijelava \& Vanclay, 2018). Assim, pode ser interessante entender a licença social como um continuum de múltiplas licenças obtidas em vários níveis da sociedade ou a partir de diferentes lugares e horários específicos, exigindo uma mudança de comportamento que perceba a importância dessas questões (Dare et al., 2014; Gehman, Thompson, Alessi, Allen, \& Goss, 2016; Harvey, 2014).

Enquanto a licença social representa uma mudança nas relações de poder, essa mudança acaba limitada por pressões discursivas para legitimar as operações de mineração, restringir as questões de licença social ao nível local, minimizar as imposições regulatórias, marginalizar a dissidência e administrar a reputação (Parsons, Lacey, \& Moffat, 2014). Por esse motivo, as campanhas de LSO não podem se basear apenas na acumulação e apresentação de evidências científicas, mas devem envolver também expressões contemporâneas de ativismo ambiental que buscam intervenção regulatória nas práticas corporativas (Murphy-Gregory, 2018).

Embora o objetivo final de obter uma LSO seja melhorar os padrões sociais, ambientais e econômicos, há o aparente risco de decisões políticas e resultados ineficazes. Os regimes de governança devem ser adaptáveis para lidar com as mudanças de informações, atitudes, valores e crenças (Cullen-Knox, Eccleston, Haward, Lester, \& Vince, 2016).

Revista de Gestão Social e Ambiental - RGSA, São Paulo, v. 13, n. 3, p. 60-78, set./dez. 2019. 
Assim, um dos maiores desafios da LSO para o futuro compreende a mudança de uma postura reativa ou compensatória, para uma que contemple uma abordagem mais colaborativa e estratégica. Velocidade de difusão de informação que facilita engajamento da comunidade, formas de divulgação de impactos mais detalhadas para atrair investidores, governança baseada em uma estrutura de prestação de contas para avaliar desempenho e nível de interação com stakeholders e acumulação de riscos são algumas das mudanças que podem estar incluídas no cenário futuro de evolução da LSO (Jeyaretnam, 2018).

\subsection{Proposição de orientações para a LSO}

O processo pelo qual os relacionamentos são estabelecidos e mantidos é fundamental para garantir uma licença social (Lacey \& Lamont, 2014). Tendo em vista os conflitos entre os grupos de interesses envolvendo a LSO, alguns pesquisadores propõem modelos para lidar com as articulações para obtenção da LSO. Entre os fatores que contribuem para a obtenção e/ou manutenção da LSO podem ser destacados: diálogo entre os grupos de interesse (Bahr \& Nakagawa, 2017; Mercer-Mapstone, Rifkin, Louis, \& Moffat, 2017; Mercer-Mapstone, Rifkin, Moffat, \& Louis, 2017; Mercer-Mapstone et al., 2018), gerenciamento de tensões e riscos (Bice, Brueckner, \& Pforr, 2017), atenção aos fatores que influenciam resistência social (Luke, 2017), modelos de LSO para segmentos industriais em expansão no mundo baseados em estruturas já existentes (Smith, Richards, \& Colwell, 2017), a confiança como papel central nas negociações (Debrah, Mtegha, \& Cawood, 2018; Moffat \& Zhang, 2014), utilização de modelos de governança (Prno \& Slocombe, 2012) e observação ao conjunto desses fatores que interagem entre si (Zhang et al., 2015).

Uma abordagem complexa de sistemas adaptativos e resiliência pode fornecer um meio valioso de avaliar sistematicamente os fatores complexos e dinâmicos dos quais os resultados da LSO emergem (Prno \& Slocombe, 2014). Para fornecer um meio de compreender a capacidade de uma comunidade de usar a LSO, pode se considerar a incorporação de campos de ação estratégicos juntamente com estruturas de medição de LSO baseadas em capital social (Wright \& Bice, 2017).

Como forma de indicar pontos de melhorias para modelos e identificar falhas conceituais na comunicação entre as partes interessadas na licença social, a realização de questionários e entrevistas é adotada por diversos autores. Richert et al. (2015) observaram que não é provável que as pessoas sejam contra projetos de petróleo e gás, já que estes trazem benefícios econômicos para o Estado, apesar da avaliação não tão elevada quanto a aceitação social, e constatou que o uso de compensações de biodiversidade marinha melhoraria a LSO do setor. Smits, Van Leeuwen e Van Tatenhove (2017) ilustraram, a partir de resultados de entrevistas com grupos de interesse, como o nível da licença social para operar está influenciando a licença política que, por sua vez, influencia a licença legal: a estrutura legal agora inclui um número maior de interações obrigatórias com as partes interessadas para aumentar a legitimidade de produção e a construção da confiança pessoal. Wilson (2016) verificou a percepção local das pessoas em relação a uma empresa de óleo e gás, e constatou que onde ocorre uma dependência da indústria e o poder é centralizada longe das comunidades, há uma chance consideravelmente menor de as comunidades locais serem capazes de influenciar uma LSO. Zhang, Measham e Moffat (2018), por meio da análise de um questionário sobre uma proposta hipotética de mineração, destacaram a importância da consulta e comunicação com a comunidade local e, sobretudo, o comprometimento com o envolvimento da comunidade. $\mathrm{O}$ ajuste às circunstâncias locais não significa apenas que uma empresa internacional tem que se adaptar à legislação nacional local, mas tem que ir além e se relacionar com os negócios locais e atender às necessidades de todos os tipos de partes interessadas (Nysten-Haarala, Klyuchnikova, \& Helenius, 2015).

Os desafios ao estabelecer uma LSO são significativos para as empresas de mineração, pensando neles, Prno (2013) estabeleceu cinco princípios orientadores que podem auxiliá-las a superar as circunstâncias mutáveis e complexas que, frequentemente, caracterizam os contextos da

Revista de Gestão Social e Ambiental - RGSA, São Paulo, v. 13, n. 3, p. 60-78, set./dez. 2019. 
atividade mineral, mas que também podem ser utilizadas como norte por outras tipologias de empreendimento. As lições a serem seguidas consistem em considerar que: (1) O contexto é fundamental; (2) Uma licença social para operar é construída sobre relacionamentos; (3) A sustentabilidade é uma preocupação dominante para as comunidades; (4) A provisão de benefícios locais e a participação pública desempenham um papel crucial; e (5) A adaptabilidade é necessária para confrontar a complexidade.

Assim, encontram-se recomendações para a prática da LSO, mas percebe-se a inexistência de um padrão claro e amplamente reconhecido, fazendo com que a LSO permaneça como um conceito abstrato. E embora uma padronização da LSO não reflita uma garantia contra seu mau uso e reinvindicações não contempladas, a necessidade de um padrão ou processo universalmente aceito para classificação dos stakeholders, e os motivos pelos quais eles conferem ou não uma LSO, ainda é indispensável para propor soluções referentes a complexidade normativa da LSO (Brueckner \& Eabrasu, 2018).

\section{CONSIDERAÇÕES FINAIS}

Com o objetivo de analisar como a literatura tem tratado sobre o tema da Licença Social para Operar, este artigo realizou uma revisão sistemática da literatura combinando critérios de busca e triagem de artigos em bases científicas de dados. O resultado obtido na busca de artigos referentes à licença social indica que esse tema possui um número razoável de publicações, com sua maioria nos últimos cinco anos, mostrando ser um tema de ascensão recente. Os periódicos de maior publicação foram Impact Assessmen tand Project Appraisal, Journal of Cleaner Production e Resources Policy. As palavras-chave mais utilizadas pelos autores analisados foram a palavra "social" (65), "operate" (30), "licence" (22), e "license" (19). A maior parte dos artigos utilizou como metodologia o estudo de caso, seguido do método de revisão da literatura. Dentre os artigos revisados, foi possível perceber que os empreendimentos de mineração são frequentemente citados pelos autores, mas além deles outras tipologias e atividades vêm sendo retratadas pela literatura, tais como hidrelétricas, estudos sobre o contexto social da captura e armazenamento de carbono, gestão da água em larga escala, cultivo de energia celulósica e ecoturismo. As relações entre a LSO e o tema da Responsabilidade Social Corporativa são contempladas na maior parte dos artigos, mostrando uma conexão entre os instrumentos na gestão dos conflitos entre a instalação e operação das empresas e stakeholders. A Austrália se destacou tanto como o país de origem das instituições de maior parte dos primeiros autores como dos estudos de caso trabalhados.

A LSO necessita que se tenha uma comunicação bem clara e efetiva entre comunidade e setor empresarial, de modo que seja considerada em longo prazo e contemple eventuais mudanças nas necessidades dos grupos interessados envolvidos. Porém, a literatura tem retratado que a prática da LSO tem enfrentado desafios, como, por exemplo, a distância entre a conceptualização teórica e sua aplicação nos contextos mutáveis da realidade corporativa; ou o perigo da ferramenta de que, ao ser aplicada a diferentes áreas da indústria, tenha seu entendimento real confundido, enfraquecendo o seu propósito.

Pensando nos desafios, alguns autores propõem modelos ou orientações para a solução de problemas e melhorias no processo do licenciamento social. Alguns deles indicam a coleta de informações, por meio de pesquisas e questionários acerca dos conceitos e expectativas que cada grupo de interesse possui em relação à LSO; com base nesses dados, é possível entender como as relações entre esses grupos se comportam e aplicar modelos focados nos principais elementos observados para uma situação estudada.

De uma maneira bem resumida, a literatura aponta que a função da LSO, diante da maior atenção dada ao ambiental no contexto socioambiental, é trazer enfoque na resolução dos conflitos sociais trazidos pelo empreendimento e na preocupação e atendimento às minorias socialmente mais vulneráveis; ela precisa desenvolver uma postura mais estratégica ao invés de ser reativa e compensatória; e é necessário o desenvolvimento de um padrão claro e amplamente reconhecido 
para sua prática, de modo que deixe de ser um conceito abstrato. Assim, será possível que a LSO realmente atenda aos interesses da comunidade ao invés de legitimar práticas que favorecem as grandes empresas.

Espera-se que nos próximos anos sejam publicados mais trabalhos na área, e que a ciência brasileira também possa conduzir estudos sobre como a LSO vem sendo aplicada na prática nacional. Esses estudos devem abordar as perspectivas de diversos segmentos de empresas e interações entre os stakeholders quanto à prática da LSO, com enfoque em uma postura mais proativa por parte das empresas e poder público e, ao mesmo tempo, pensando em orientação prática ou, até mesmo, uma padronização de metodologia para os processos que envolvem a validação e manutenção de uma LSO.

A licença social é um imperativo para a regulação ambiental e desempenha um papel fundamental no destaque de preocupações que são, de certa forma, negligenciadas ou mesmo ignoradas. Estes atributos da LSO possibilitam mudar o modo pelo qual as questões sociais e ambientais são tratadas pelo setor privado e também como estão inseridas nas políticas públicas.

Conforme os resultados aqui apresentados, o tema Licença Social para Operar (LSO) mostra-se emergente nas pesquisas cientificas e significativo para os pesquisadores da área, sendo a revisão sistemática da literatura realizada relevante para pesquisas futuras.

\section{REFERÊNCIAS}

Bahr, K., \& Nakagawa, M. (2017). The effect of bidirectional opinion diffusion on social license to operate. Environment, Development and Sustainability, 19(4), 1235-1245.

Baumber, A. (2018). Energy cropping and social licence: what's trust got to do with it? Biomass and Bioenergy, 108, 25-34.

Bice, S. (2014). What gives you a social licence? An exploration of the social licence to operate in the Australian mining industry. Resources, 3(1), 62-80.

Bice, S., \& Moffat, K. (2014). Social licence to operate and impact assessment. Impact Assessment and Project Appraisal, 32(4), 257-262.

Bice, S., \& Brueckner, M.; Pforr, C. (2017). Putting social license to operate on the map: A social, actuarial and political risk and licensing model (SAP Model). Resources Policy, 53, 46-55.

Bickford, N., Smith, L., Bickford, S., Bice, M. R., \& Ranglack, D. H. (2017). Evaluating the role of CSR and SLO in ecotourism: collaboration for economic and environmental sustainability of arctic resources. Resources, 6(2), 21.

Billing, S. L. (2018). Using public comments to gauge social licence to operate for finfish aquaculture: Lessons from Scotland. Ocean and Coastal Management, 165, 401-415.

Boutilier, R. G., \& Thomson, I. (2011). Modelling and measuring the social license to operate: fruits of a dialogue between theory and practice. Social Licence, 1779-96.

Boutilier, R. G. (2014). Frequently asked questions about the social licence to operate. Impact Assessment and Project Appraisal, 32(4), 263-272.

Browne, A. L., Stehlik, D., \& Buckley, A. (2011). Social licences to operate: for better not for worse; for richer not for poorer? The impacts of unplanned mining closure for "fence line" residential communities. Local Environment, 16(7), 707-725.

Brueckner, M., Durey, A., Pforr, C., \& Mayes, R. (2014). The civic virtue of developmentalism: On the mining industry's political licence to develop Western Australia. Impact Assessment and Project Appraisal, 32(4), 315-326. 
Brueckner, M., Eabrasu, M. (2018). Pinning down the social license to operate (SLO): The problem of normative complexity. Resources Policy, 59, 217-226.

CEE - Collaboration for Environmental Evidence. (2013). Guidelines for Systematic Review and Evidence Synthesis in Environmental Management. Recuperado em 10 outubro, 2018, de http://environmentalevidence.org/wp-content/uploads/2014/06/Review-guidelinesversion-4.2finalPRINT.pdf.

Cooney, J. (2017). Reflections on the 20th anniversary of the term 'social licence'. Journal of Energy \& Natural Resources Law, 35(2), 197-200.

Cruz, T, L., Matlaba, V. J., Mota, J. A., Oliveira Júnior, C., Santos, J. F., Cruz, L. N., \& Demétrio Neto, E. N. (2019). Assessing Sustainability in Mining Industry: Social License to Operate and Other Economic and Social Indicators in Canaã dos Carajás (Pará, Brazil). In: Leal Filho, W., Brito, P. R. B., \& Frankenberger, F. (eds). International Business, Trade and Institutional Sustainability. World Sustainability Series. Springer, 555-573.

Cullen-Knox, C., Eccleston, R., Haward, M., Lester, E., \& Vince, J. (2016). Contemporary challenges in environmental governance: technology, governance and the social licence. Environmental Policy and Governance, 27(1), 3-13.

Cullen-Knox, C., Haward, M., Jabour, J., Ogier, E., \& Tracey, S. R. (2017). The social licence to operate and its role in marine governance: Insights from Australia. Marine Policy, 79, 70-77.

Curran, G. (2017). Social licence, corporate social responsibility and coal seam gas: framing the new political dynamics of contestation. Energy Policy, 101, 427-435.

Dare, M., Schirmer, J., \& Vanclay, F. (2014). Community engagement and social licence to operate. Impact Assessment and Project Appraisal, 32(3), 188-197.

Debrah, A. A., Mtegha, H., \& Cawood, F. (2018). Social licence to operate and the granting of mineral rights in sub-Saharan Africa: exploring tensions between communities, governments and multi-national mining companies. Resources Policy, 56, 95-103.

Demajorovic, J., Lopes, J. C., \& Santiago, A. L. F. (2019). The Samarco case disaster; a grave challenge to social license to operate discourse. Resources Policy, 61, 273-382.

Ehrnstrom-Fuentes, M., \& Kröger, M. (2017). In the shadows of social licence to operate: untold investment grievances in Latin America. Journal of Cleaner Production, 141, 346-358.

Filer, C., \& Gabriel, J. (2018). How could nautilus minerals get a social licence to operate the world's first deep sea mine? Marine Policy, 95, 394-400.

Franks, D. M., Davis, R., Bebbington, A. J., Ali, S. H., Kemp, D., \& Scurrah, M. (2014). Conflict translates environmental and social risk into business costs. Proceedings of the National Academy of Sciences, 111(21), 7576-7581.

Gaviria, E. M. (2015). A “licença social para operar" na indústria da mineração: uma aproximação a suas apropriações e sentidos. Revista Brasileira de Estudos Urbanos e Regionais, 17(2), 138-154.

Gehman, J., Thompson, D. Y., Alessi, D. S., Allen, D. M., \& Goss, G. G. (2016). Comparative analysis of hydraulic fracturing wastewater practices in unconventional shale development: Newspaper coverage of stakeholder concerns and social license to operate. Sustainability, 8(9), 912.

Gough, C., Cunningham, R., \& Mander, S. (2018). Understanding key elements in establishing a social license for CCS: an empirical approach. International Journal of Greenhouse Gas Control, $68,16-25$.

Gunningham, N., Kagan, R. A., \& Thornton, D. (2004). Social license and environmental protection: why businesses go beyond compliance. Law \& Social Inquiry, 29(2), 307-341. 
Hall, N., Lacey, J., Carr-Cornish, S., \& Dowd, A. (2015). Social licence to operate: Understanding how a concept has been translated into practice in energy industries. Journal of Cleaner Production, $86,301-310$.

Hall, N. L. (2015). Community corporate engagement on water resource impacts: opportunities for Social Licence to Operate. Australian Journal of Water Resources, 19(2), 109-115.

Harvey, B. (2014). Social development will not deliver social licence to operate for the extractive sector. Extractive Industries and Society, 1(1), 7-11.

Harvey, B., \& Bice, S. (2014). Social impact assessment, social development programmes and social licence to operate: tensions and contradictions in intent and practice in the extractive sector. Impact Assessment and Project Appraisal, 32(4), 327-335.

Holley, E. A., \& Mitcham, C. (2016). The pebble mine dialogue: a case study in public engagement and the social license to operate. Resources Policy, 47, 18-27.

Jeyaretnam, T. (2018). The evolving nature of social licence to operate. Climate Change and Sustainability, (5).

Jijelava, D., \& Vanclay, F. (2014). Social licence to operate through a gender lens: the challenges of including women's interests in development assistance projects. Impact Assessment and Project Appraisal, 32(4), 283-293.

Jijelava, D., \& Vanclay, F. (2017). Legitimacy, credibility and trust as the key components of a social licence to operate: an analysis of BP's projects in Georgia. Journal of Cleaner Production, 140, 1077-1086.

Jijelava, D., \& Vanclay, F. (2018). How a large project was halted by the lack of a social Licence to operate: Testing the applicability of the Thomson and Boutilier model. Environmental Impact Assessment Review, 73, 31-40.

Jones, T.M., Felps, W., \& Bigley, G.A. (2007). Ethical theory and stakeholder- related decisions: the role of stakeholder culture. Academy of Management Review, University of Washington Business School, 32(1), 137-155.

Kelly, R., Pecl, G. T., \& Fleming, A. (2017). Social licence in the marine sector: a review of understanding and application. Marine Policy, 81, 21-28.

Koivurova, T., Buanes, A., Riabova, L., Didyk, V., Ejdemo, T., Poelzer, G., Taavo, P., \& Lesser, P. (2015). 'Social license to operate': a relevant term in Northern European mining? Polar Geography, 38(3), 194-227.

Lacey, J., \& Lamont, J. (2014). Using social contract to inform social licence to operate: an application in the Australian coal seam gas industry. Journal of Cleaner Production, 84(1), 831839.

Litmanen, T., Jartti, T., \& Rantala, E. (2016). Refining the preconditions of a social licence to operate (SLO): reflections on citizens' attitudes towards mining in two Finnish regions. Extractive Industries and Society, 3(3), 782-792.

Luke, H. (2017). Social resistance to coal seam gas development in the Northern Rivers region of Eastern Australia: proposing a diamond model of social license to operate. Land Use Policy, 69, 266-280.

Martinez, C., \& Franks, D. M. (2014). Does mining company-sponsored community development influence social licence to operate? Evidence from private and state-owned companies in Chile. Impact Assessment and Project Appraisal, 32(4), 294-303. 
McIntyre, M. L., Murphy, S. A., \& Sirsly, C. T. (2015). Do firms seek social license to operate when stakeholders are poor? Evidence from Africa. Corporate Governance, 15(3), 306-314.

Meesters, M. E., \& Behagel, J. H. (2017). The social licence to operate: ambiguities and the neutralization of harm in Mongolia. Resources Policy, 53(C), 274-282.

Mercer-Mapstone, L., Rifkin, W., Louis, W., \& Moffat, K. (2017). Meaningful dialogue outcomes contribute to laying a foundation for social licence to operate. Resources Policy, 53, 347-355.

Mercer-Mapstone, L., Rifkin, W., Moffat, K., \& Louis, W. (2017). Conceptualising the role of dialogue in social licence to operate. Resources Policy, 54, 137-146.

Mercer-Mapstone, L., Rifkin, W., Louis, W. R., \& Moffat, K. (2018). Company-community dialogue builds relationships, fairness, and trust leading to social acceptance of Australian mining developments. Journal of Cleaner Production, 184, 671-677.

Moffat, K., \& Zhang, A. (2014). The paths to social licence to operate: an integrative model explaining community acceptance of mining. Resources Policy, 39(1), 61-70.

Murphy-Gregory, H. (2018). Governance via persuasion: environmental NGOs and the social licence to operate. Environmental Politics, 27(2), 320-340.

Nysten-Haarala, S., Klyuchnikova, E., \& Helenius, H. (2015). Law and self-regulation - Substitutes or complements in gaining social acceptance? Resources Policy, 45, 52-64.

Owen, J. R., \& Kemp, D. (2013). Social licence and mining: a critical perspective. Resources Policy, 38(1), 29-35.

Parsons, R., Lacey, J., \& Moffat, K. (2014). Maintaining legitimacy of a contested practice: how the minerals industry understands its "social licence to operate". Resources Policy, 41(1), 83-90.

Parsons, R., \& Moffat, K. (2014). Integrating impact and relational dimensions of social licence and social impact assessment. Impact Assessment and Project Appraisal, 32(4), 273-282.

Prno, J. (2013). An analysis of factors leading to the establishment of a social licence to operate in the mining industry. Resources Policy, 38(4), 577-590.

Prno, J., \& Scott Slocombe, D. (2012). Exploring the origins of "social license to operate" in the mining sector: Perspectives from governance and sustainability theories. Resources Policy, 37(3), $346-357$.

Prno, J., \& Slocombe, D. S. (2014). A systems-based conceptual framework for assessing the determinants of a social license to operate in the mining industry. Environmental Management, 53(3), 672-689.

Provasnek, A. K., Sentic, A., \& Schmid, E. (2017). Integrating eco-innovations and stakeholder engagement for sustainable development and a social license to operate. Corporate Social Responsibility and Environmental Management, 24(3), 173-185.

Ranängen, H.; Lindman, Å. (2018). Exploring corporate social responsibility practice versus stakeholder interests in Nordic mining. Journal of Cleaner Production, 197, 668-677.

Richert, C., Rogers, A., \& Burton, M. (2015). Measuring the extent of a social license to operate: the influence of marine biodiversity offsets in the oil and gas sector in Western Australia. Resources Policy, 43, 121-129.

Ruckstuhl, K.; Thompson-Fawcett, M.; Rae, H. (2014). Māori and mining: indigenous perspectives on reconceptualising and contextualising the social licence to operate. Impact Assessment and Project Appraisal, 32(4), 304-314. 
Santiago, A. L. F., \& Demajorovic, J. (2016). Social license to operate: a case study from a Brazilian mining industry'. Latin American Journal of Management for Sustainable Development, 3, 19-34.

Santiago, A. L. F., Demajorovic, J , Rosseto, D. E., \& Aledo, A. (2018). A evolução da licença social para operar e critérios de influência para a sua concessão: uma revisão sistemática integrativa. In: Engema, 2018, 20 São Paulo. Anais do Engema.

Smith, D. C., Richards, J. M., \& Colwell, R. J. (2017). Where "shale" we go from here: Opportunities and challenges in shale plays located outside the USA. Journal of World Energy Law and Business, 10(3), 159-219.

Smits, C. C. A., Van Leeuwen, J., \& Van Tatenhove, J. P. M. (2017). Oil and gas development in Greenland: a social license to operate, trust and legitimacy in environmental governance. Resources Policy, 53, 109-116.

Van Putten, I. E., Cvitanovic, C., Fulton, E., Lacey, J., Kelly, R. (2018). The emergency of social licence necessitates reforms in environmental regulation. Ecology and Society, 23 (3), 24.

Vanclay, F. (2017). Principles to gain a social licence to operate for green initiatives and biodiversity projects. Current Opinion in Environmental Sustainability, 29, 48-56.

Wedin, A., Lundgren, M., Mushi, C., Suleiman, L., \& Gustafsson, J.-E. (2013). Food versus fuel: the case of the Makeni community in Sierra Leone. WIT Transactions on Ecology and the Environment, 170, 37-48.

Wessman, H., Kohl, O. S. J., Kinnunen, P., Saarivuori, E., \& Mroueh, U. (2014). Water and society: mutual challenges for eco-efficient and socially acceptable mining in Finland. Journal of Cleaner Production, 84(1), 289-298.

Westoby, P., \& Lyons, K. (2016). Privatising development and environmental management: undermining social license in the Ugandan plantation forest sector. Environmental Sociology, 2(3), $265-274$.

Wilson, E. (2016). What is the social licence to operate? Local perceptions of oil and gas projects in Russia's Komi Republic and Sakhalin Island. Extractive Industries and Society, 3(1), 73-81.

Wright, S., \& Bice, S. (2017). Beyond social capital: a strategic action fields approach to social licence to operate. Resources Policy, 52, 284-295.

Zhang, A., Moffat, K., Lacey, J., Wang, J., Gonzalez, R., Uribe, K., Cui, L., \& Dai, Y. (2015), Understanding the social licence to operate of mining at the national scale: A comparative study of Australia, China and Chile. Journal of Cleaner Production, 108, 1063-1072.

Zhang, A., Measham, T. G., \& Moffat, K. (2018). Preconditions for social licence: the importance of information in initial engagement. Journal of Cleaner Production, 172, 1559-1566. 